\title{
In Situ Shell-Isolated Nanoparticle-Enhanced Raman Spectroscopy to Unravel Sequential Hydrogenation of Phenylacetylene over Platinum Nanoparticles
}

\author{
Caterina S. Wondergem, Thomas Hartman, and Bert M. Weckhuysen*(0) \\ Inorganic Chemistry and Catalysis, Debye Institute for Nanomaterials Science, Utrecht University, Universiteitsweg 99,3584 CG \\ Utrecht, The Netherlands
}

\author{
Supporting Information
}

\begin{abstract}
Shell-isolated nanoparticle-enhanced Raman spectroscopy (SHINERS) is quickly developing into a powerful characterization tool in heterogeneous catalysis. In this work, we employ Pt catalysts supported on $\mathrm{Au} @ \mathrm{SiO}_{2}$ shell-isolated nanoparticles to study hydrogenation reactions. First, we demonstrate the facile preparation of $\mathrm{Pt} / \mathrm{Au} @ \mathrm{SiO}_{2}$ and its characterization by using adsorption of $\mathrm{CO}$ as probe molecule. Next, we use the adsorption and hydrogenation of phenylacetylene as a model reaction for the interaction of triple bonds and aromatic rings with catalytic Pt surfaces. We show that the applicability of SHINERS is not limited to inherently gaseous compounds, thereby expanding the applicability of the technique to more complex systems.

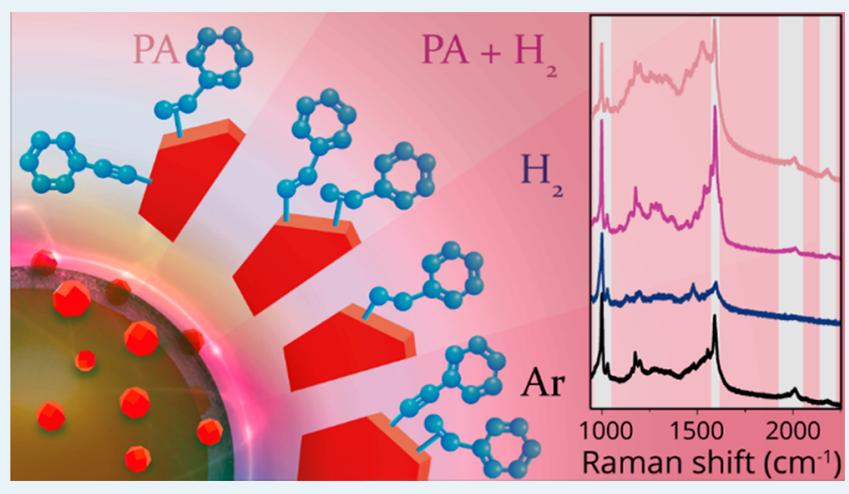
Furthermore, by using nonparticipating side groups as labels, we observe the sequential hydrogenation of phenylacetylene into styrene and ultimately ethylbenzene upon reaction with $\mathrm{H}_{2}$. Upon the absence of $\mathrm{H}_{2}$, the reverse reaction takes place with those molecules still adsorbed onto the catalyst surface, which allowed a more detailed understanding of the reaction mechanism and the assignment of Raman peaks. This strengthens the position of SHINERS as an easily applicable surface sensitive technique that can be used to study a wide variety of chemical reactions in the field of heterogeneous catalysis.
\end{abstract}

KEYWORDS: Raman spectroscopy, heterogeneous catalysis, Au nanoparticles, in situ SHINERS, hydrogenation

\section{INTRODUCTION}

Understanding metal-adsorbate interactions is of fundamental importance for rational catalyst design. ${ }^{1}$ Raman spectroscopy offers the ability to study such interactions, making it a powerful tool in heterogeneous catalysis research by offering fundamental insights into structure-performance relationships. These insights could help in the design of more optimal solid catalysts for both new and already existing chemical processes, increasing conversion, activity, and selectivity and reducing waste and greenhouse gases.,

However, the applicability of Raman spectroscopy to nanoscale systems is limited due to the poor detection limit, typically around $1-10 \mathrm{wt} \%$ of the probed area. ${ }^{4}$ Surfaceenhanced Raman spectroscopy (SERS) solves that problem by employing gold and silver nanoparticles (NPs). ${ }^{4-6} \mathrm{Au}$ and $\mathrm{Ag}$ $\mathrm{NPs}$ of sufficient size (starting at $>10 \mathrm{~nm}$; optimum around $100 \mathrm{~nm})^{7}$ possess surface plasmons which, when excited with light of the resonant frequency, can create an electromagnetic field that enhances the Raman scattering of species on or within several $\mathrm{nm}$ of the surface. Using this principle, in ideal cases, SERS has been reported to enhance Raman signals with factors of up to $10^{14}$, corresponding to even single molecule levels. ${ }^{8-11}$ For catalysis this means that SERS has the potential to not only elucidate structure-performance relationships through studying adsorption of species of interest in metal surfaces but also through the detection of short-lived intermediates or even transition states. ${ }^{12}$ However, the surface plasmons and their resonance SERS is based on can influence chemical reactions to be studied by injecting "hot electrons", causing photocatalytic side-reactions. ${ }^{4,13}$ Furthermore, low stability of the $\mathrm{Ag}$ and $\mathrm{Au}$ NPs limits reaction conditions to be studied. These challenges can be overcome by using shellisolated nanoparticle-enhanced Raman spectroscopy (SHINERS). ${ }^{14}$ For SHINERS, the SERS-active NPs are coated with a thin layer of dielectric oxide, for example $\mathrm{SiO}_{2}$. This thin layer not only increases the thermal and chemical stability of the SERS-active core, several studies have showed that the $\mathrm{SiO}_{2}$ layer also confines hot electrons to the core. ${ }^{13,15}$ They demonstrated this by studying the reduction of 4-nitrothiophenol (4-NTP) to 4-aminothiophenol (4-ATP) over a

Received: July 16, 2019

Revised: September 6, 2019

Published: September 11, 2019 

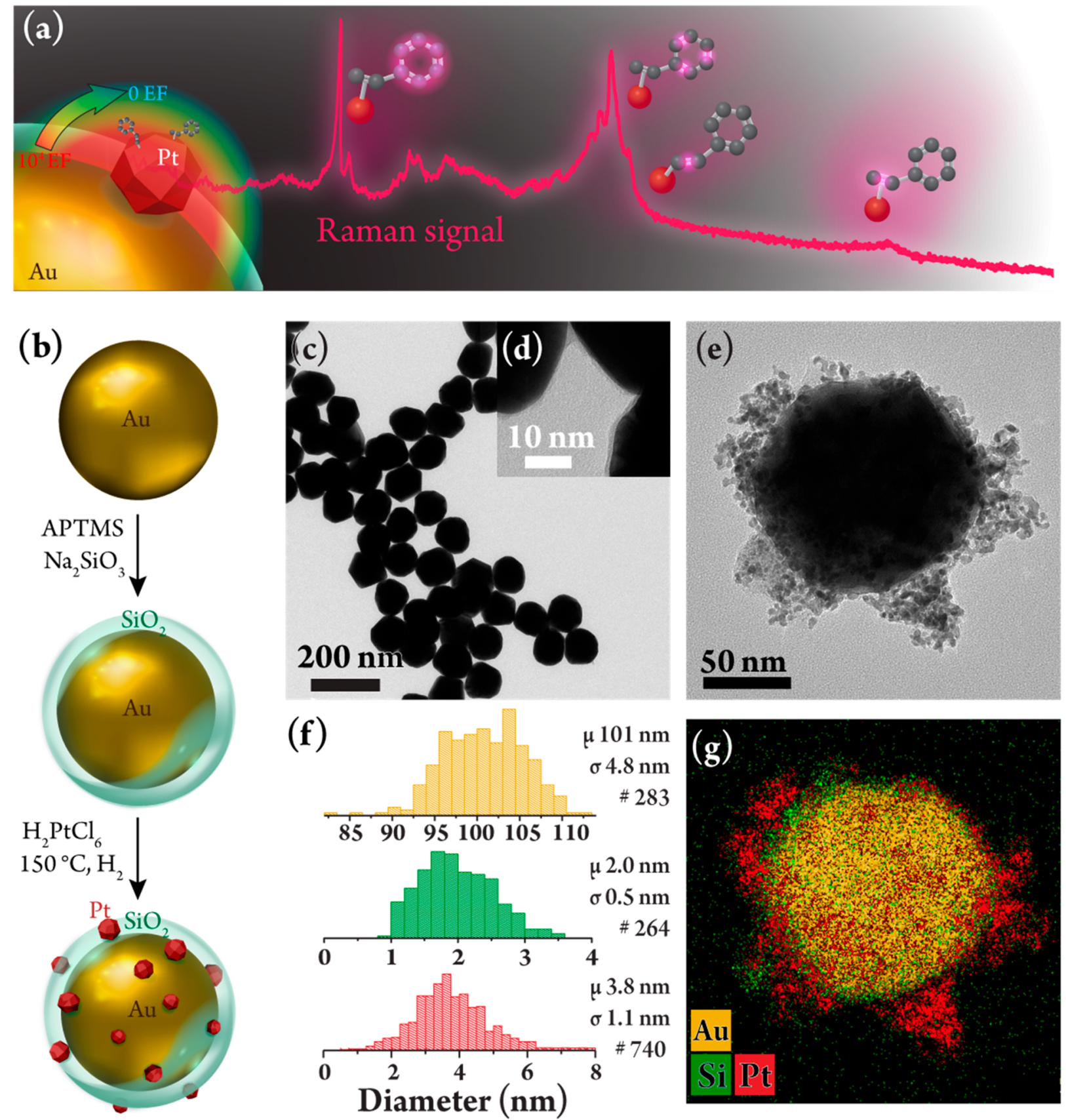

(f)
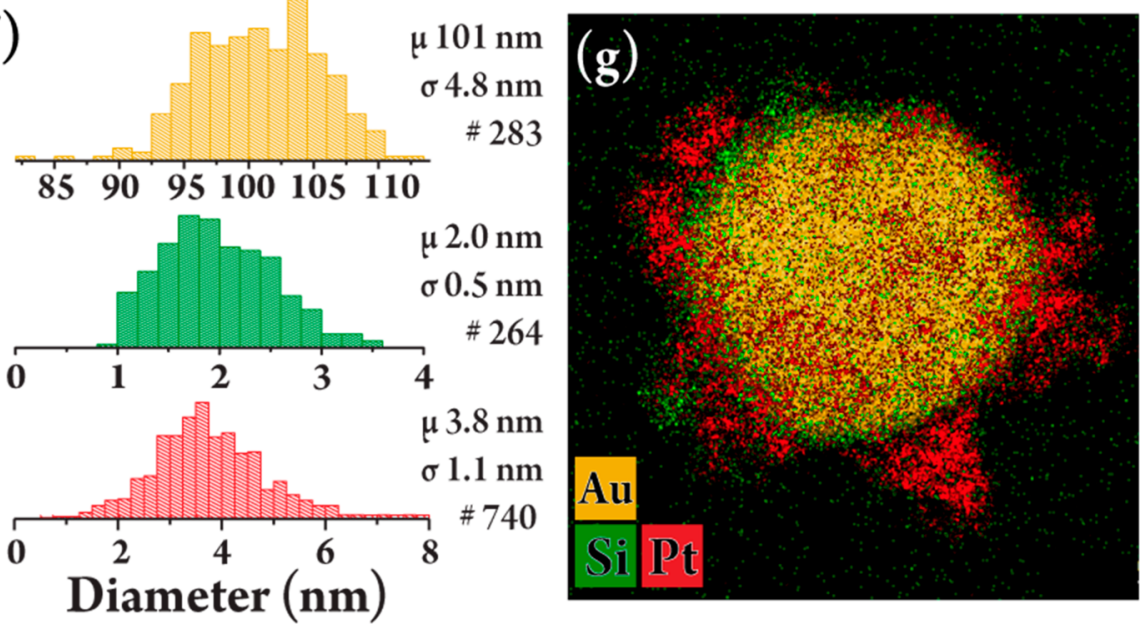

Figure 1. (a) Schematic illustrating the goal of this study, which is to observe the conversion of phenylacetylene to styrene and ethylbenzene over a Pt hydrogenation catalyst placed inside the enhanced electromagnetic field of a SERS-active Au@SiO ${ }_{2}$ shell-isolated nanoparticle (SHIN). (b) Schematic visualization of the $\mathrm{Pt} / \mathrm{Au} @ \mathrm{SiO}_{2}$ catalyst/SHIN preparation. (c) Transmission electron microscopy (TEM) images of the Au core nanoparticles, (d) $\mathrm{Au} @ \mathrm{SiO}_{2}$ SHINs, and (e) of a Pt/Au@SiO $\mathrm{S}_{2}$ catalyst/SHIN. (f) Size distributions based on TEM measurements. The Au core (top, yellow) NPs have a mean diameter of $101 \mathrm{~nm}$ and are coated with a $2 \mathrm{~nm}$ layer of $\mathrm{SiO}_{2}$ (middle, green). Pt NPs (bottom, red) are $\sim 3.8 \mathrm{~nm}$ in diameter. (g) Elemental map of (e) confirming the presence of Pt (red) on top of the $\mathrm{Au} @ \mathrm{SiO}_{2}$ (yellow, green, respectively) SHINs. Note that the $\mathrm{Pt} / \mathrm{Au} @ \mathrm{SiO}_{2}$ TEM samples were prepared after in situ SHINERS experiments by redispersion from the Si wafer and transfer to a TEM grid. Therefore, the aggregation state and dispersion of Pt NPs over the $\mathrm{Au} @ \mathrm{SiO}_{2}$ SHINs is not a representative image of those during in situ experiments.

Au catalyst. Hot electrons are known to influence this reaction by catalyzing dimerization to $4,4^{\prime}$-dimercaptoazobenzene (DMAB) ${ }^{16-18}$ Using a catalyst comprised of SERS-inactive colloidal $\mathrm{Au} \mathrm{NPs}$ of $<5 \mathrm{~nm}$ supported on $\mathrm{Au} @ \mathrm{SiO}_{2}$ shellisolated nanoparticles (SHINs) prevented the formation of $\mathrm{DMAB}$, thus proving that hot electrons could not participate in the reaction. A similar principle where colloidal nanoparticle catalysts were deposited on SHINs was used by the group of
Tian to study hydrogenation of $4-\mathrm{NTP}^{19}$ and $\mathrm{CO}$ adsorption and oxidation $^{20}$ on transition metal/Au@SiO 2 SHINs. Furthermore, our group has recently reported that catalyst/ SHIN systems can also be prepared by impregnation of SHINs with a catalyst precursor followed by in situ reduction. ${ }^{21,22}$ Subsequently, support effects were studied by investigating CO hydrogenation over $\mathrm{Ru}$ and $\mathrm{Rh}$ catalysts supported on $\mathrm{Au} @$ $\mathrm{SiO}_{2}$ and $\mathrm{Au} @ \mathrm{TiO}_{2}$ SHINs. 
In this study, we will extend the applicability of SHINERS to reactions beyond those involving 4-NTP and simple gases, such as CO. For the first time, we report an in situ SHINERS study of sequential hydrogenation reactions of organic molecules, more specifically phenylacetylene to styrene and finally ethylbenzene, on the surface of a $\mathrm{Pt} / \mathrm{Au} @ \mathrm{SiO}_{2}$ catalyst, as shown in Figure 1a.

Normally, this chemical reaction is carried out in the liquid phase, at slightly elevated temperatures and pressures. ${ }^{23}$ Furthermore, often a Lindlar catalyst composed of $\mathrm{Pd}$ poisoned with $\mathrm{S}$ and $\mathrm{Pb}$ is used to selectively produce alkenes and prevent further hydrogenation to alkanes. ${ }^{24}$ However, we will prepare $\mathrm{Au} @ \mathrm{SiO}_{2}$ SHINs and deposit catalytically active Pt catalysts on the surface by wet impregnation and in situ reduction as reported by Hartman et al. ${ }^{21}$ We will show that SHINERS is a suitable technique to study hydrogenation reactions of alkynes and alkenes and that aromatic side groups can be used as spectroscopic tags to monitor the reaction. Furthermore, by using phenylacetylene vapor saturated in $\mathrm{N}_{2}$, we show that the application of SHINERS to heterogeneous catalysis is not limited to intrinsically gaseous compounds.

\section{EXPERIMENTAL SECTION}

Preparation of Au@SiO 2 SHINs. The preparation of Au@ $\mathrm{SiO}_{2}$ SHINs is described in detail elsewhere. ${ }^{25}$ In short, gold seeds were synthesized using the Turkevich method ${ }^{26}$ to obtain $\mathrm{Au}$ seeds of approximately $17 \mathrm{~nm}$ in Millipore water $(\mathrm{MQ}$; resistivity $18.2 \mathrm{M} \Omega \cdot \mathrm{cm})\left(\mathrm{HAuCl}_{4} \times 3 \mathrm{H}_{2} \mathrm{O} 99.99 \%\right.$ obtained from Alfa Aesar; sodium tricitrate dihydrate, 99\%, Sigma-Aldrich). NPs were grown to a size of approximately $100 \mathrm{~nm}$ using $\mathrm{NH}_{2} \mathrm{OH} \times \mathrm{HCl}$ (99.995\%, Sigma-Aldrich) as a mild reducing agent. ${ }^{27}$ Subsequent $\mathrm{SiO}_{2}$ growth was realized through the APTMS (99\%, Sigma-Aldrich)/sodium silicate (27\%, Sigma-Aldrich) method to yield Au@SiO ${ }_{2}$ SHINs. $^{25}$ Successful synthesis of these particles was confirmed as per the characterization data presented in Figure $1 c, d$, and $f$ and the Supporting Information Figures $\mathrm{S} 1-3$.

Preparation of Pt/Au@SiO ${ }_{2}$ SHINs. A $50 \mu \mathrm{L}$ portion of a $10 \mathrm{mM} \mathrm{H}_{2} \mathrm{PtCl}_{6}$ (99.995\%, Sigma-Aldrich) solution was mixed with $0.5 \mathrm{mLAu} @ \mathrm{SiO}_{2}$ SHINs. After mixing and equilibrating for $\sim 30 \mathrm{~min}, 15 \mu \mathrm{L}$ of the mixture was dropcast on an Si wafer and was vacuum-dried. The sample was cleaned in an Ossila E511 UV-Ozone Cleaner for $15 \mathrm{~min}$ before in situ SHINERS experiments. The sample was placed in a Linkam Cell and $\mathrm{Pt}$ was reduced in situ at $150{ }^{\circ} \mathrm{C}$ under $50 \% \mathrm{H}_{2}$ flow in Ar for $1 \mathrm{~h}$, while monitoring the process with SHINERS on a Renishaw inVia confocal Raman microscope using a $20 \times$ objective (NA $=0.4), 1200 \mathrm{l} / \mathrm{mm}$ grating, $0.12-1.96 \mathrm{~mW}$ laser intensity with $785 \mathrm{~nm}$ laser excitation.

Characterization. $\mathrm{Au}$ and $\mathrm{Au} @ \mathrm{SiO}_{2} \mathrm{NP}$ size and LSPR were investigated with UV-vis absorption spectroscopy on a Varian Cary $50 \mathrm{UV}$-visible spectrophotometer in quartz cuvettes with an optical path length of $10.00 \mathrm{~mm}$. Au and Au@ $\mathrm{SiO}_{2} \mathrm{NP}$ size and layer thickness were investigated on a FEI Tecnai 12 and FEI Tecnai 20 transmission electron microscope (TEM), operating at 120 and $200 \mathrm{keV}$, respectively. Samples were prepared by drying $15 \mu \mathrm{L}$ of the dispersions onto Formvar/carbon-coated 300 mesh copper TEM grids (Van Loenen Instruments). The $\mathrm{Pt} / \mathrm{Au} @ \mathrm{SiO}_{2}$ catalyst/SHINs were investigated with elemental analysis using high-angle-annular dark field scanning transmission electron microscopy (HAADF-STEM) and energy dispersive X-ray spectroscopy (EDX) on a FEI Talos F200 electron microscope operating at
$200 \mathrm{keV}$. Samples were prepared by redispersing in situ reduced samples in isopropanol and subsequent transfer to Formvar/carbon-coated 300 mesh copper TEM grids.

Raman Spectroscopy of Reference Compounds. Raman spectra of pure phenylacetylene, styrene, and ethylbenzene were measured in a quartz cuvette with an optical path length of $10.00 \mathrm{~mm}$ using an Avantes Raman probe in combination with a $532 \mathrm{~nm}$ Cobalt laser set to $51 \mathrm{~mW}$ connected to an Andor EMCCD detector equipped with a $1200 \mathrm{l} / \mathrm{mm}$ grating.

CO Adsorption Experiments. After in situ reduction, 10 $\mathrm{mL} / \mathrm{min} \mathrm{CO}$ and $40 \mathrm{~mL} / \mathrm{min}$ Ar were introduced into the Linkam Cell at $150{ }^{\circ} \mathrm{C}$. Adsorption of $\mathrm{CO}$ was monitored with in situ SHINERS on a Renishaw inVia confocal Raman microscope using a $20 \times$ objective (NA = 0.4), $1200 \mathrm{l} / \mathrm{mm}$ grating, $0.12-1.96 \mathrm{~mW}$ laser intensity with $785 \mathrm{~nm}$ laser excitation.

Phenylacetylene Adsorption Experiments. $\mathrm{N}_{2}$ saturated with phenylacetylene was introduced into the Linkam Cell. Adsorption was studied at $25,40,60$, and $80{ }^{\circ} \mathrm{C}$ for 30 min each and was monitored with in situ SHINERS on a Renishaw inVia confocal Raman microscope using a $20 \times$ objective ( $\mathrm{NA}=0.4), 1200 \mathrm{l} / \mathrm{mm}$ grating, $0.12-1.96 \mathrm{~mW}$ laser intensity with $785 \mathrm{~nm}$ laser excitation.

Phenylacetylene Hydrogenation Experiments. Phenylacetylene hydrogenation was studied by flowing $\mathrm{H}_{2}$ over the catalyst at $60{ }^{\circ} \mathrm{C}$. The feed consisted of a $1: 1$ mixture of $\mathrm{H}_{2}$ with either $\mathrm{N}_{2}$ saturated with phenylacetylene, or with Ar. Dehydrogenation conditions were achieved by flowing only Ar. The total flow was always $50 \mathrm{~mL} / \mathrm{min}$. Hydrogenation was monitored using in situ SHINERS on a Renishaw inVia confocal Raman microscope using a $20 \times$ objective, $1200 \mathrm{l} / \mathrm{mm}$ grating, $0.12-1.96 \mathrm{~mW}$ laser intensity with $785 \mathrm{~nm}$ laser excitation.

\section{RESULTS}

Characterization of Pt/Au@SiO 2 Catalyst/SHINs. Figure $1 \mathrm{~b}$ shows a schematic representation of the preparation of $\mathrm{Pt} / \mathrm{Au} @ \mathrm{SiO}_{2}$. The transmission electron microscopy (TEM) images of the corresponding Au NPs at the top, the Au@SiO 2 shell-isolated nanoparticles (SHINs) in the middle, and the $\mathrm{Pt}$ / $\mathrm{Au} @ \mathrm{SiO}_{2}$ catalyst/SHINs at the bottom are shown in Figure $1 \mathrm{c}-\mathrm{e}$, respectively, along with the accompanying particle size distributions in Figure 1f. The $101 \mathrm{~nm}$ diameter of the Au core lies close to the reported optimum for enhanced Raman scattering, ${ }^{7}$ whereas the ultrathin $\mathrm{SiO}_{2}$ coating of $2.0 \pm 0.5 \mathrm{~nm}$ is a good trade-off between minimizing the loss in signal intensity and obtaining a pinhole-free coating. ${ }^{19,25,28}$ Small nanostructures can be observed covering the Au@SiO 2 SHINs, which were confirmed to consist of Pt by the energy dispersive $\mathrm{X}$-ray spectroscopy (EDX) map in Figure 1g. Particle size analysis of $740 \mathrm{Pt}$ NPs gives an average size of $3.8 \mathrm{~nm}$ and a standard deviation of $1.1 \mathrm{~nm}$. Taking into account the thickness of the $\mathrm{SiO}_{2}$ layer, this means that on average the outer surface of the Pt NPs is about $5.5 \mathrm{~nm}$ away from the $\mathrm{Au}$ core. As the SERS effect is a very local effect with most intense enhancement factors arising within $\sim 5 \mathrm{~nm}$ of the $\mathrm{Au} \mathrm{NP}$ surface, ${ }^{4}$ this potentially means that we cannot observe processes occurring on the entire Pt NP surface. In order to test this, we performed $\mathrm{CO}$ adsorption experiments on the $\mathrm{Pt} /$ $\mathrm{Au} @ \mathrm{SiO}_{2}$ samples. First, samples were cleaned with UV/ozone and then reduced in situ in a Linkam Cell at $150{ }^{\circ} \mathrm{C}$ for $1 \mathrm{~h}$ in a 1:1 mixture of $\mathrm{H}_{2}$ and Ar. The Raman spectra were recorded 

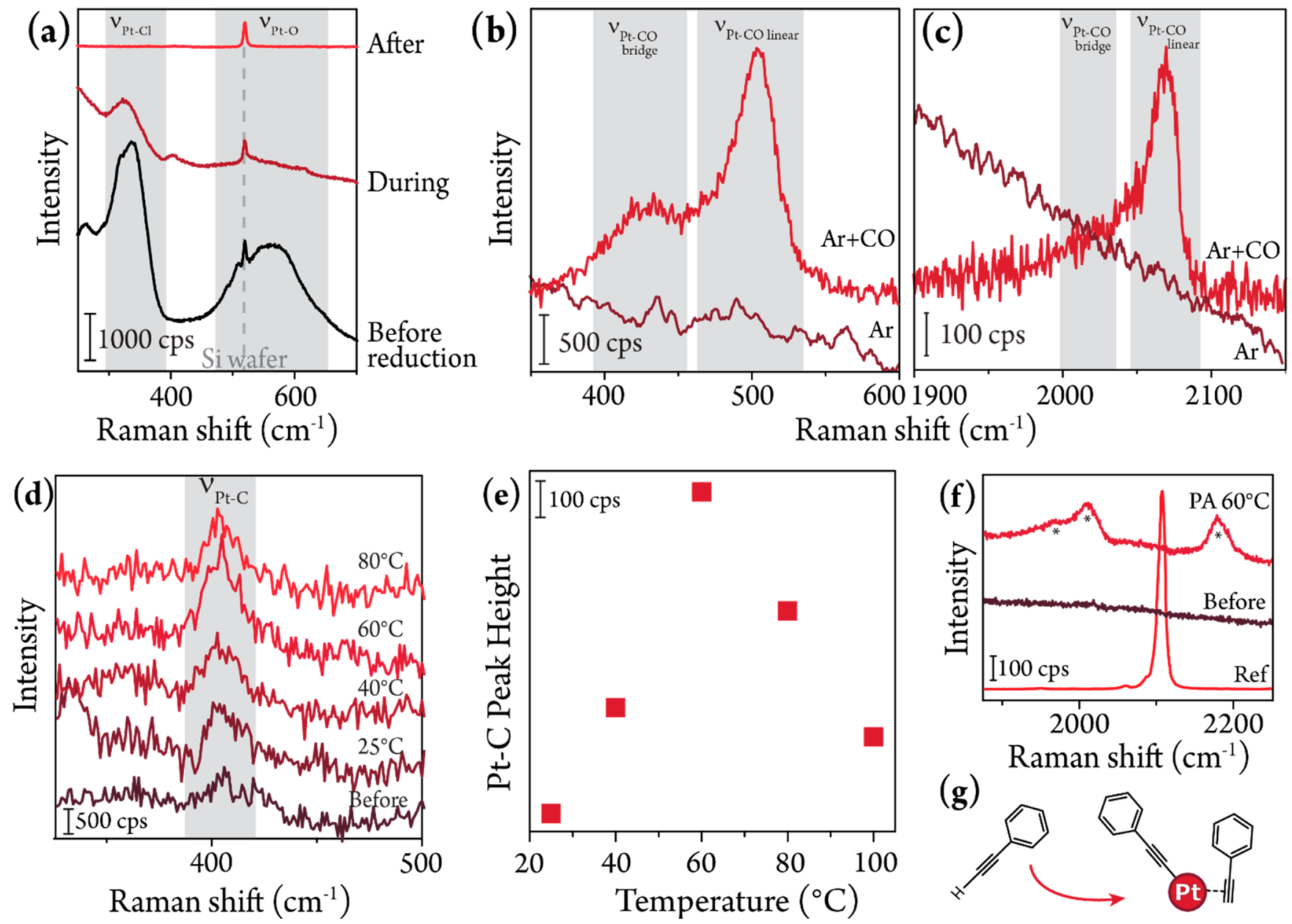

Figure 2. (a) In situ SHINER spectra of reduction of $\mathrm{Pt}_{x} \mathrm{Cl}_{y}\left(330 \mathrm{~cm}^{-1}\right)$ and $\mathrm{Pt}_{x} \mathrm{O}_{z}\left(560 \mathrm{~cm}^{-1}\right)$ to metallic Pt. Note the sharp peak at $520 \mathrm{~cm}{ }^{-1}$ originating from the Si wafer used to support the Pt/Au@SiO 2 catalyst/SHINs. (b, c) In situ SHINER spectra of CO adsorption at $150{ }^{\circ} \mathrm{C}$. Both peaks assigned to $\mathrm{CO}$ in a bridge $\left(\mathrm{b}, 430 \mathrm{~cm}^{-1}\right.$; c, $\left.2010 \mathrm{~cm}^{-1}\right)$ and linear $\left(\mathrm{b}, 505 \mathrm{~cm}^{-1}\right.$; c, $\left.2070 \mathrm{~cm}^{-1}\right)$ configuration on Pt were observed. (d-g) Phenylacetylene adsorption on activated $\mathrm{Pt} / \mathrm{Au} @ \mathrm{SiO}_{2}$ catalyst/SHINs. (d) Metal-adsorbate stretching region where a peak assigned to Pt-C stretching can be observed at different temperatures. (e) Peak height for the $\mathrm{Pt}-\mathrm{C}$ stretching vibration showing an optimum at $60^{\circ} \mathrm{C}$. (f) $\mathrm{C} \equiv \mathrm{C}$ stretching region. The reference spectrum of phenylacetylene exhibits an intense peak originating from free $\mathrm{C} \equiv \mathrm{C}-\mathrm{H}$ at $2105 \mathrm{~cm}^{-1}$, whereas phenylacetylene chemisorbed on Pt at $60{ }^{\circ} \mathrm{C}$ shows three peaks at 1960, 2010, and $2190 \mathrm{~cm}^{-1}$, indicated with asterisks. (g) Schematic of phenylacetylene chemisorption on Pt NPs through $\sigma$ - and $\pi$-interactions.

using a $785 \mathrm{~nm}$ excitation source, which is known to give limited potential plasmonic side reactions in combination with $\mathrm{Au}$ nanoparticles (NPs) under the applied conditions. ${ }^{12,22}$ Figure 2a shows the SHINER spectra during reduction. At the start of the experiment, two broad bands can be observed, namely one around $330 \mathrm{~cm}^{-1}$ for $\mathrm{Pt}-\mathrm{Cl}$ stretching vibrations from the platinum precursor, and one around $560 \mathrm{~cm}^{-1}$, which does not originate from $\mathrm{Pt}-\mathrm{Cl}$ vibrations. ${ }^{29}$ During UV/ozone treatment, the platinum chloride precursor becomes partially oxidized, resulting in the appearance of $\mathrm{Pt}-\mathrm{O}$ stretching vibrations of amorphous platinum oxide. ${ }^{30-32}$ Upon introducing reducing conditions, the bands start to decrease in intensity and after an hour they are completely gone, indicating the formation of (Raman-inactive) metallic Pt. ${ }^{33}$ Subsequently, the in situ cell was flushed with $\mathrm{Ar}$ and $\mathrm{CO}$ was introduced at 150 ${ }^{\circ} \mathrm{C}$. Figure $2 \mathrm{~b}$ and $\mathrm{c}$ shows the low and high wavenumber region of the SHINER spectra obtained during in situ CO adsorption. The low wavenumber region is known to show bands arising from metal-adsorbate stretching vibrations. Indeed, when we compare our $\mathrm{CO}$ adsorption spectra to those in the literature, we can see that we observe similar peaks corresponding to $\mathrm{CO}$ adsorption on a Pt surface..$^{20,21,34}$ In particular, we observe two different vibrations, one due to $\mathrm{CO}$ adsorbed on $\mathrm{Pt}$ in a bridge configuration at $430 \mathrm{~cm}^{-1}$ and one corresponding to $\mathrm{CO}$ adsorbed in a linear fashion at $505 \mathrm{~cm}^{-1}$. Characteristic peaks for these two configurations can also be found in the high wavenumber region, looking at the $\mathrm{C}-\mathrm{O}$ stretching vibration. Again, we observe a vibration associated with bridged $\mathrm{CO}$ as a shoulder at $2010 \mathrm{~cm}^{-1}$, while at 2070 $\mathrm{cm}^{-1}$ we can see $\mathrm{C}-\mathrm{O}$ stretching of $\mathrm{CO}$ adsorbed in a linear configuration. These experiments show that (1) the Pt NPs are within the range for signal enhancement from the SERS effect; (2) we can observe interactions of adsorbates with multiple sites of the Pt catalyst; and (3) we have sufficient accessible Pt surface that can be used to study heterogeneous catalytic reactions. Finally, as no shift in the stretching vibrations or bands corresponding to $\mathrm{CO}$ on $\mathrm{Au}$ were observed, we can state that our $\mathrm{SiO}_{2}$ layer is pinhole-free and our SHINs are stable (for additional tests, see Figure S3-S5). ${ }^{14,35}$

Phenylacetylene Adsorption. Adsorption of phenylacetylene on $\mathrm{Pt} / \mathrm{Au} @ \mathrm{SiO}_{2}$ catalyst/SHINs was investigated at various temperatures to determine the optimum conditions 

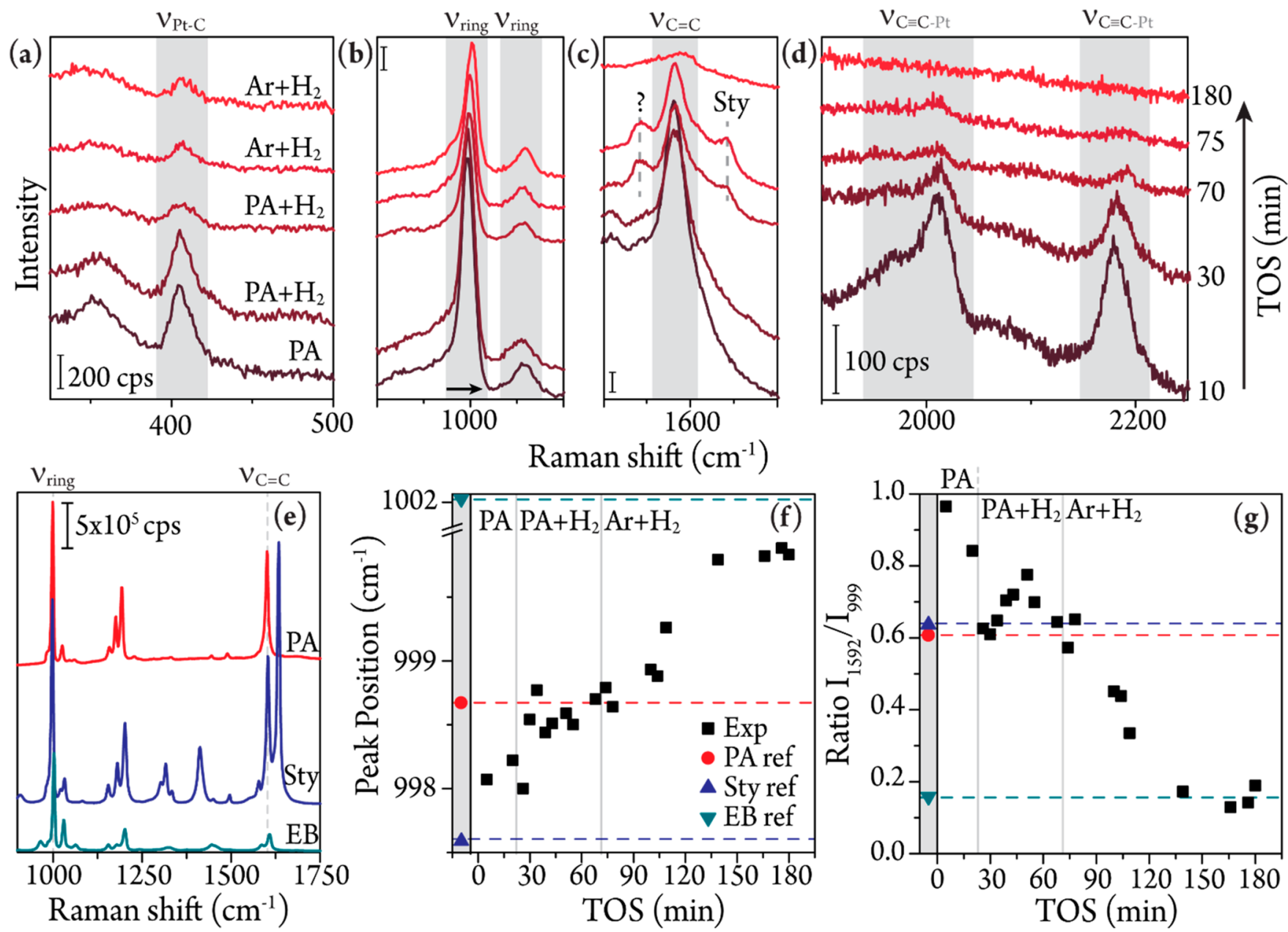

Figure 3. (a-d) Hydrogenation of phenylacetylene over $\mathrm{Pt} / \mathrm{Au} @ \mathrm{SiO}_{2}$ catalyst/SHINs at $60{ }^{\circ} \mathrm{C}$ with time-on-stream (TOS). (a) Pt-C stretching region. Upon hydrogenation of phenylacetylene, the peak attributed to $\mathrm{Pt}-\mathrm{C}$ stretching decreases slightly and then remains constant. (b) Spectral region showing ring vibrations. Upon hydrogenation a shift to higher frequencies is observed, indicating hydrogenation occurs. (c) $\mathrm{C}=\mathrm{C}$ stretching region indicating $\mathrm{C}=\mathrm{C}$ stretching from the phenyl group. Two additional peaks attributed to $\mathrm{C}=\mathrm{C}$ stretching can be observed during hydrogenation; at higher frequencies due to $\mathrm{C}=\mathrm{C}$ stretching of the ethylene group present in styrene, and at lower frequencies due to $\pi$-bound ethylene from styrene. (d) $\mathrm{C} \equiv \mathrm{C}$ stretching region which shows complete disappearance of alkyne vibrations over the course of hydrogenation. (e) Reference spectra of phenylacetylene (PA, red), styrene (Sty, blue) and ethylbenzene (EB, green) in which ring breathing vibrations and the aromatic $\mathrm{C}=\mathrm{C}$ stretching vibrations used for further analysis are indicated. (f) Tracking the peak position of the ring breathing vibration with $\mathrm{TOS}$ shows a clear shift toward the reference position of ethylbenzene (green dashed line). Gas feed composition is indicated at the top of the graph. (g) Ratio $I_{1592} / I_{999}$ with TOS compared to reference values of phenylacetylene (red), styrene (blue), and ethylbenzene (green) indicates the formation of ethylbenzene.

for hydrogenation reactions. $\mathrm{N}_{2}$ was flowed through a bubbler filled with phenylacetylene to obtain a saturated gas feed that was led over the catalyst placed in a Linkam Cell (See Figure S6 for the experimental setup). Figure $2 \mathrm{~d}$ and e report on the $\mathrm{Pt}-\mathrm{C}$ vibration observed at $405 \mathrm{~cm}^{-1}$ as we regard it as a measure of the amount of phenylacetylene present on the $\mathrm{Pt}$ surface. $^{36,37}$ Therefore, phenylacetylene hydrogenation will be studied at the temperature for which we find an optimum in adsorption. Although no internal standard is present, by examining and focusing on the same spot on the sample, peak intensities can be reliably compared to one another within one experiment. Fitting and integration of the peak originating from the $\mathrm{Pt}-\mathrm{C}$ stretching vibration in Figure $2 \mathrm{~d}$ shows that an optimum in peak height exists at $60^{\circ} \mathrm{C}$, as displayed in Figure 2e. Figure $2 \mathrm{f}$ shows the $\mathrm{C} \equiv \mathrm{C}$ stretching region where for pure phenylacetylene we expect to see one sharp peak at $2105 \mathrm{~cm}^{-1}$. However, we observe that upon adsorption on the Pt catalyst, it splits into two distinct peaks at 2190 and $2010 \mathrm{~cm}^{-1}$ with the latter possessing a shoulder around $1960 \mathrm{~cm}^{-1}$. This indicates that adsorption only takes place through the acetylene group and not through the aromatic ring. These observations are in line with adsorption reported of phenylacetylene and other alkynes on different transition metals ${ }^{38-46}$ and are attributed to chemisorption; $\sigma$-bonding and $\sigma \pi$-complexation of a weak nature with different sites on the Pt surface, based on the relatively small shift in the $\mathrm{C} \equiv \mathrm{C}$ vibrations compared to free (phenyl)acetylene. ${ }^{43,45}$ Furthermore, surface science experiments have shown that the aromatic ring in substituted benzenes orients itself away from the surface and is therefore not involved in adsorption. ${ }^{43,46}$

Phenylacetylene adsorption SHINERS experiments were also performed on $\mathrm{Au} \mathrm{NPs}$ and $\mathrm{Au} @ \mathrm{SiO}_{2}$ SHINs for comparison (Figure S7). A discussion of these spectra shown in Figure S7 can be found in the Supporting Information.

Phenylacetylene Hydrogenation. Figure 3 shows SHINER spectra from hydrogenation of phenylacetylene to 

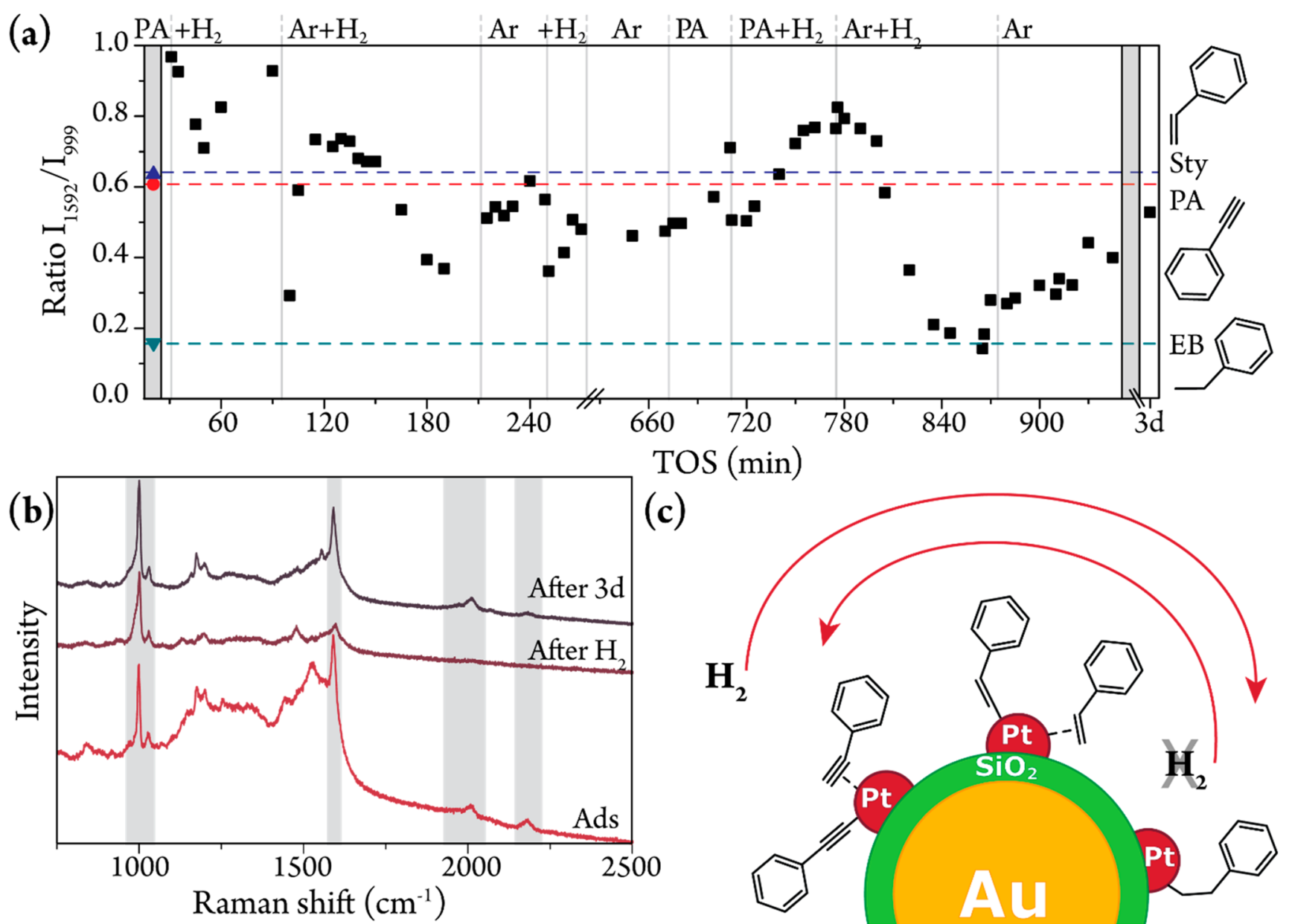

TOS (min)

(c)

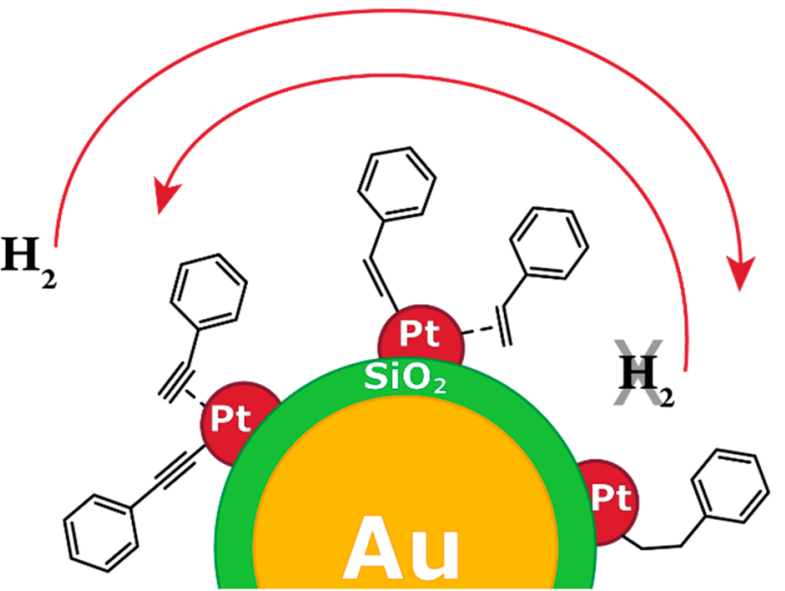

Figure 4. (a) Monitoring the ratio $I_{1592} / I_{999}$ with TOS in hydrogen-rich and hydrogen-poor gas feeds compared to the reference compounds phenylacetylene (PA, red), styrene (Sty, blue), and ethylbenzene (EB, green). The gas feed composition is indicated above the figure. In hydrogenrich environments, a clear shift toward the reference value for ethylbenzene is observed, whereas the reverse shift occurs in the absence of hydrogen. (b) Spectra of phenylacetylene adsorption at the start of the experiment (Ads), after hydrogenation (TOS = $860 \mathrm{~min}$ ), and after 3 days under pure Ar flow. (c) Scheme of phenylacetylene hydrogenation and dehydrogenation including all observed species. Note that upon changing the gas feed composition, and especially when introducing $\mathrm{H}_{2}$, the ratio $I_{1592} / I_{999}$ tends to drop. We attribute this to the high heat capacity of $\mathrm{H}_{2}$ and the fluctuations in conditions this brings about before equilibration.

styrene and ultimately ethylbenzene at $60{ }^{\circ} \mathrm{C}$ with time-onstream (TOS) under different conditions. First, $\mathrm{N}_{2}$ saturated with phenylacetylene and Ar were led over the catalyst in a 1:1 ratio. As expected based on the adsorption experiments, we observe a peak attributed to $\mathrm{Pt}-\mathrm{C}$ stretching at $405 \mathrm{~cm}^{-1}$ in Figure $3 \mathrm{a}$ and three peaks in the $\mathrm{C} \equiv \mathrm{C}$ region in Figure $3 \mathrm{~d}$. Furthermore, Figure $3 \mathrm{~b}$ shows peaks originating from ring breathing vibrations of a monosubstituted benzene around 1000 and $1030 \mathrm{~cm}^{-1}$, and in Figure $3 \mathrm{c}$ we observe a peak from aromatic $\mathrm{C}=\mathrm{C}$ stretching at $1592 \mathrm{~cm}^{-1}$. All of the peaks originating from aromatic ring vibrations appear unperturbed compared to the reference spectra in Figure $3 \mathrm{f}$ and the literature. $^{36}$ This indicates a lack of interaction between the phenyl ring and the Pt surface, and further supports adsorption solely through $\mathrm{C} \equiv \mathrm{C}$ as previously discussed.

After $30 \mathrm{~min}$, the $\mathrm{Ar}$ flow was switched to $\mathrm{H}_{2}$ and immediately a decrease in $\mathrm{C} \equiv \mathrm{C}$ stretching was observed, whereas a similar decrease was not observed in the other spectral regions. Only after $\sim 60 \mathrm{~min}$ of simultaneous phenylacetylene adsorption and hydrogenation did we observe a decrease, alongside an even further decrease in the $\mathrm{C} \equiv \mathrm{C}$ stretching peak intensities. Additionally, we observe the appearance of two new peaks in the $\mathrm{C}=\mathrm{C}$ region. Comparison to reference spectra shown in Figures $3 e$ and $\mathrm{S} 8$ shows that the peak at $\sim 1634 \mathrm{~cm}^{-1}$ can be attributed to $\mathrm{C}=\mathrm{C}$ stretching originating from the ethylene group in styrene, whereas the peak at $\sim 1571 \mathrm{~cm}^{-1}$ does not match any of the peaks in the reference spectra. However, Mrozek and Weaver have reported similar peaks for $\pi$-bound ethylene on Pt electrodes studied with SERS. $^{31}$ Monitoring the presence of this band over the experiment as displayed in Figure S9 shows that it is only present alongside the $1634 \mathrm{~cm}^{-1}$ peak from the ethylene group in styrene, thereby indicating that the peak at $1571 \mathrm{~cm}^{-1}$ can be attributed to $\pi$-bound styrene on $\mathrm{Pt}$. Subsequently, we turned off the phenylacetylene flow and continued the experiments with a gas feed composed of $\mathrm{H}_{2}$ and Ar to ensure full hydrogenation of all adsorbed species. A further decrease in peaks originating from $\mathrm{C} \equiv \mathrm{C}$ stretching vibrations is observed, alongside the disappearance of those corresponding to ethylene. The aromatic $\mathrm{C}=\mathrm{C}$ stretching vibrations at 1592 $\mathrm{cm}^{-1}$ remain present, although with very little intensity. Furthermore, both $\mathrm{Pt}-\mathrm{C}$ vibrations and ring breathing vibrations remain present, but whereas the $\mathrm{Pt}-\mathrm{C}$ stretching vibrations remains at $405 \mathrm{~cm}^{-1}$, the ring breathing vibrations 
exhibit a shift to higher frequencies. Based on the reference spectra in Figure 3e and S8, this shift indicates a decrease in conjugation. Tracking the position of the ring breathing vibration at $999 \mathrm{~cm}^{-1}$ by deconvolution of the spectra (See Figure $\mathrm{S} 10)^{47}$ and subsequent comparison with reference spectra as displayed in Figure $3 \mathrm{f}$ show that the peak position moves in the direction of the reference value for ethylbenzene under hydrogenation conditions. Further inspection of the reference spectra also shows that the ratio of the peak intensity of the aromatic $\mathrm{C}=\mathrm{C}$ stretching vibration $\left(I_{1592}\right)$ to the peak intensity of the ring breathing vibration at $999 \mathrm{~cm}^{-1}\left(I_{999}\right)$ differs among phenylacetylene, styrene, and ethylbenzene. Upon fitting of the experimental spectra, ${ }^{47}$ the ratio $I_{1592} / I_{999}$ was compared to those of the reference compounds and again a trend was observed that indicates the formation of ethylbenzene, as illustrated in Figure 3g. Interestingly, switching back to pure Ar flow leads to an upward shift of the ratio $I_{1592} / I_{999}$, back to the values of styrene and phenylacetylene (Figure S11).

To determine whether we are witnessing dehydrogenation or simply readsorption of residual phenylacetylene, cycles of hydrogenation-dehydrogenation experiments were performed, as reported in Figure 4. Figure 4a shows the ratio $I_{1592} / I_{999}$ with TOS under different gas feed compositions: pure phenylacetylene in $\mathrm{N}_{2}$ (PA), $\mathrm{PA}$ and $\mathrm{H}_{2}, \mathrm{Ar}$ and $\mathrm{H}_{2}$, and pure $\mathrm{Ar}$ as indicated above the graph. Upon introduction of hydrogen, the ratio $I_{1592} / I_{999}$ decreases to indicate ethylbenzene formation. However, as soon as $\mathrm{H}_{2}$ is removed from the gas feed and we flow pure Ar, the ratio starts to increase again, away from the ethylbenzene reference value. This trend can be observed throughout the entire experiment and is also reflected in the ring breathing peak position (Figure S12). After leaving the cell under continuous Ar flow for 3 days, the ratio $I_{1592} / I_{999}$ reaches the reference values for styrene and phenylacetylene. Over the course of this experiment, the intensity of the $\mathrm{Pt}-\mathrm{C}$ stretching vibration was monitored for changes in the amount of adsorbates, presented in Figure S13. Inspection of this intensity shows that after equilibration the $\mathrm{Pt}-\mathrm{C}$ peak height remains at constant values, excluding the possibility for readsorption of residual phenylacetylene which would be reflected in an increase in peak height. Figure $4 b$ shows spectra at the start of the experiment, when phenylacetylene was adsorbed, at the end of the hydrogenation experiments at TOS $=860 \mathrm{~min}$ and after keeping the sample under constant Ar flow for 3 days. Ring breathing, $\mathrm{C}=\mathrm{C}$ and $\mathrm{C} \equiv \mathrm{C}$ stretching vibrations indicated in the figure show, first, that the aromatic ring stays intact, second, that no peaks ascribed to styrene are observed (see also Figure S9), and, third, $\mathrm{C} \equiv \mathrm{C}$ stretching vibrations disappear upon hydrogenation but return in the absence of hydrogen, showing that the ethylbenzene that remains on the catalyst surface after hydrogenation is dehydrogenated back to phenylacetylene.

Based on the spectral observations we made, we propose that in our experiments phenylacetylene hydrogenation occurs as follows: Phenylacetylene is adsorbed on the Pt surface, giving rise to a $\mathrm{Pt}-\mathrm{C}$ stretch at $405 \mathrm{~cm}^{-1}$ and a splitting of the $\mathrm{C} \equiv \mathrm{C}$ band into three bands at 1960, 2010, and $2190 \mathrm{~cm}^{-1}$ due to chemisorption ( $\sigma$-bonding and weak $\sigma \pi$-complexation) and physisorption. The absence of free $\mathrm{C}_{2} \equiv \mathrm{C}_{1}-\mathrm{H}$ stretching vibrations and lack of distortion in ring vibrations confirm adsorption takes place solely through the triple bond. Upon hydrogenation, we observe styrene both in a linear, $\sigma$-bound fashion at $1621 \mathrm{~cm}^{-1}$ and $\pi$-bound through its ethylene group at $1571 \mathrm{~cm}^{-1}$, depending on whether a hydrogen is inserted first in $\mathrm{C}_{1}$ or $\mathrm{C}_{2}$, respectively. Upon complete disappearance of both the $\mathrm{C} \equiv \mathrm{C}$ stretching vibrations and vibrations ascribed to styrene, ethylbenzene is observed. The presence of the $\mathrm{Pt}-\mathrm{C}$ stretching peak allows us to assign this peak to linear $\sigma$ bonding of the terminal alkyl $\mathrm{C}_{1}$ atom to the Pt surface, resulting in the scheme presented in Figure 4c. This is in line with the observation of a lack of $\pi$-bonding styrene species upon dehydrogenation, as logically linearly bound styrene should be formed. Furthermore, after dehydrogenation the peak ratios of the different $\mathrm{C} \equiv \mathrm{C}$ stretching vibrations differ from those observed during adsorption. The peaks at 2010 and $1960 \mathrm{~cm}^{-1}$ we attribute therefore to chemisorbed species: The most intense peak at $2010 \mathrm{~cm}^{-1}$ we assign to $\mathrm{C}_{2} \equiv \mathrm{C}_{1}-\mathrm{Pt} \sigma$ bonding, and its shoulder at $1960 \mathrm{~cm}^{-1}$ to the weak $\sigma \pi$ complexation of the acetylene group with $\mathrm{Pt}$, as $\pi$-interaction of conjugated bonds parallel to the surface is often reported to result in a redshift in wavenumber. ${ }^{31,48,49}$ Finally, we propose the peak at $2190 \mathrm{~cm}^{-1}$ arises from adsorption at a less stable configuration or site, ${ }^{40}$ based on the low intensity of the peak observed upon dehydrogenation.

\section{CONCLUSIONS}

Herein, we showed that in situ SHINERS allows for identification of catalyst-adsorbate interactions on the nanoscale, using the sequential gas-phase hydrogenation of phenylacetylene to styrene and ultimately ethylbenzene over $\mathrm{Pt} / \mathrm{Au} @ \mathrm{SiO}_{2}$ catalyst/SHINs as a model reaction. This work demonstrates that in situ SHINERS can be used to monitor hydrogenation reactions while they occur on the surface of the catalyst, proving its value as a generally applicable characterization method in the field of heterogeneous catalysis. By employing a setup and method that allows the reverse reaction to be studied, we were able to give more detailed Raman peak assignment and gain understanding of the reaction mechanism. Furthermore, we show that spectator or unreacting side groups can be used as an internal reference, opening up the possibility to study reactions of chemical groups with an inherent low Raman cross-section and reactions of complicated molecules over heterogeneous catalysts using in situ SHINERS.

\section{ASSOCIATED CONTENT}

\section{Supporting Information}

The Supporting Information is available free of charge on the ACS Publications website at DOI: 10.1021/acscatal.9b03010.

UV-vis spectroscopy of Au seeds, Au NPs, and Au@ $\mathrm{SiO}_{2}$ SHIN dispersions; TEM analysis data of Au seeds, $\mathrm{Au}$ NPs, Au@SiO 2 SHINs, and additional images of Pt/ $\mathrm{Au} @ \mathrm{SiO}_{2}$ catalyst/SHINs after reaction; pinhole and SERS-activity test for $\mathrm{Au} @ \mathrm{SiO}_{2}$ SHINs; experimental setup for in situ SHINERS experiments; additional SHINER spectra; full reference spectra of phenylacetylene, styrene, and ethylbenzene; monitoring presence of peaks related to styrene; fitting of spectra; monitoring $\mathrm{Pt}-\mathrm{C}$ stretching peak intensity; tracking ring breathing peak positions with TOS (PDF)

\section{AUTHOR INFORMATION}

\section{Corresponding Author}

*Email: b.m.weckhuysen@uu.nl.

ORCID

Bert M. Weckhuysen: 0000-0001-5245-1426 


\section{Funding}

This work is financially supported by a Technology Area (TA) grant from The Netherlands Organization of Scientific Research (NWO), Albemarle Catalysts, BASF, and TNO.

\section{Notes}

The authors declare no competing financial interest.

\section{ACKNOWLEDGMENTS}

We acknowledge Hans Meeldijk for (HAADF)-STEM and EDX measurements.

\section{REFERENCES}

(1) Bell, A. T. The Impact of Nanoscience on Heterogeneous Catalysis. Science 2003, 299, 1688-1691.

(2) Lee, E. L.; Wachs, I. E. In Situ Raman Spectroscopy of $\mathrm{SiO}_{2}$ Supported Transition Metal Oxide Catalysts: An Isotopic ${ }^{18} \mathrm{O}-{ }^{16} \mathrm{O}$ Exchange Study. J. Phys. Chem. C 2008, 112, 6487-6498.

(3) Lee, E. L.; Wachs, I. E. In Situ Spectroscopic Investigation of the Molecular and Electronic Structures of $\mathrm{SiO}_{2}$ Supported Surface Metal Oxides. J. Phys. Chem. C 2007, 111, 14410-14425.

(4) Schlücker, S. Surface-Enhanced Raman Spectroscopy: Concepts and Chemical Applications. Angew. Chem., Int. Ed. 2014, 53, 47564795.

(5) Fleischmann, M.; Hendra, P. J.; McQuillan, A. J. Raman Spectra of Pyridine Adsorbed at a Silver Electrode. Chem. Phys. Lett. 1974, 26, $163-166$.

(6) Hartman, T.; Wondergem, C. S.; Kumar, N.; Van Den Berg, A.; Weckhuysen, B. M. Surface- and Tip-Enhanced Raman Spectroscopy in Catalysis. J. Phys. Chem. Lett. 2016, 7, 1570-1584.

(7) Fang, P.-P.; Li, J.-F.; Yang, Z.-L.; Li, L.-M.; Ren, B.; Tian, Z.-Q. Optimization of SERS Activities of Gold Nanoparticles and GoldCore-Palladium-Shell Nanoparticles by Controlling Size and Shell Thickness. J. Raman Spectrosc. 2008, 39, 1679-1687.

(8) Zhang, R.; Zhang, Y.; Dong, Z. C.; Jiang, S.; Zhang, C.; Chen, L. G.; Zhang, L.; Liao, Y.; Aizpurua, J.; Luo, Y.; Yang, J. L.; Hou, J. G. Chemical Mapping of a Single Molecule by Plasmon-Enhanced Raman Scattering. Nature 2013, 498, 82-86.

(9) Sigle, D. O.; Kasera, S.; Herrmann, L. O.; Palma, A.; De Nijs, B.; Benz, F.; Mahajan, S.; Baumberg, J. J.; Scherman, O. A. Observing Single Molecules Complexing with Cucurbit[7]Uril through Nanogap Surface-Enhanced Raman Spectroscopy. J. Phys. Chem. Lett. 2016, 7, 704-710.

(10) Etchegoin, P. G.; Le Ru, E. C. A Perspective on Single Molecule SERS: Current Status and Future Challenges. Phys. Chem. Chem. Phys. 2008, 10, 6079.

(11) Pozzi, E. A.; Zrimsek, A. B.; Lethiec, C. M.; Schatz, G. C.; Hersam, M. C.; Van Duyne, R. P. Evaluating Single-Molecule Stokes and Anti-Stokes SERS for Nanoscale Thermometry. J. Phys. Chem. C 2015, 119, 21116-21124.

(12) Van Schrojenstein Lantman, E. M.; De Peinder, P.; Mank, A. J. G.; Weckhuysen, B. M. Separation of Time-Resolved Phenomena in Surface- Enhanced Raman Scattering of the Photocatalytic Reduction of p-Nitrothiophenol. ChemPhysChem 2015, 16, 547-554.

(13) Zhang, K.; Xu, N.; Jia, M.; Li, R.; Huang, M. In Situ Detection of Hot-Electron-Induced Photocatalytic Reduction Using Au@Ag, $\mathrm{Au} @ \mathrm{Ag}_{2} \mathrm{~S}$, and $\mathrm{Au} @ \mathrm{SiO}_{2}$ Core-Shell Nanoparticles. J. Appl. Phys. 2019, 125, 183101.

(14) Li, J. F.; Huang, Y. F.; Ding, Y.; Yang, Z. L.; Li, S. B.; Zhou, X. S.; Fan, F. R.; Zhang, W.; Zhou, Z. Y.; Wu, D. Y.; Ren, B.; Wang, Z. L.; Tian, Z. Q. Shell-Isolated Nanoparticle-Enhanced Raman Spectroscopy. Nature 2010, 464, 392-395.

(15) Xie, W.; Walkenfort, B.; Schlücker, S. Label-Free SERS Monitoring of Chemical Reactions Catalyzed by Small Gold Nanoparticles Using 3D Plasmonic Superstructures. J. Am. Chem. Soc. 2013, 135, 1657-1660.

(16) Van Schrojenstein Lantman, E. M.; Gijzeman, O. L. J.; Mank, A. J. G.; Weckhuysen, B. M. Investigation of the Kinetics of a Surface
Photocatalytic Reaction in Two Dimensions with Surface-Enhanced Raman Scattering. ChemCatChem 2014, 6, 3342-3346.

(17) Liu, Y.; Zhao, Y.; Zhang, L.; Yan, Y.; Jiang, Y. Controllable Plasmon-Induced Catalytic Reaction by Surface-Enhanced and TipEnhanced Raman Spectroscopy. Spectrochim. Acta, Part A 2019, 219, 539-546.

(18) Kumar, N.; Wondergem, C. S.; Wain, A. J.; Weckhuysen, B. M. In Situ Nanoscale Investigation of Catalytic Reactions in the Liquid Phase Using Zirconia-Protected Tip-Enhanced Raman Spectroscopy Probes. J. Phys. Chem. Lett. 2019, 10, 1669-1675.

(19) Zhang, H.; Zhang, X. G.; Wei, J.; Wang, C.; Chen, S.; Sun, H. L.; Wang, Y. H.; Chen, B. H.; Yang, Z. L.; Wu, D. Y.; Li, J. F.; Tian, Z. Q. Revealing the Role of Interfacial Properties on Catalytic Behaviors by in Situ Surface-Enhanced Raman Spectroscopy. J. Am. Chem. Soc. 2017, 139, 10339-10346.

(20) Zhang, H.; Wang, C.; Sun, H. L.; Fu, G.; Chen, S.; Zhang, Y. J.; Chen, B. H.; Anema, J. R.; Yang, Z. L.; Li, J. F.; Tian, Z. Q. In Situ Dynamic Tracking of Heterogeneous Nanocatalytic Processes by Shell-Isolated Nanoparticle-Enhanced Raman Spectroscopy. Nat. Commun. 2017, 8, 1-8.

(21) Hartman, T.; Weckhuysen, B. M. Thermally Stable $\mathrm{TiO}_{2}$ - and $\mathrm{SiO}_{2}$-Shell-Isolated $\mathrm{Au}$ Nanoparticles for In Situ Plasmon-Enhanced Raman Spectroscopy of Hydrogenation Catalysts. Chem. - Eur. J. 2018, 24, 3734-3741.

(22) Hartman, T.; Wondergem, C.; Weckhuysen, B. M. Practical Guidelines for Shell-Isolated Nanoparticle-Enhanced Raman Spectroscopy of Heterogeneous Catalysts. ChemPhysChem 2018, 19, 2461-2467.

(23) Carturan, G.; Cocco, G.; Facchin, G.; Navazio, G. Phenylacetylene Hydrogenation with $\mathrm{Pd}, \mathrm{Pt}$ and $\mathrm{Pd}-\mathrm{Pt}$ Alloy Catalysts Dispersed on Amorphous Supports: Effect of $\mathrm{Pt} / \mathrm{Pd}$ Ratio on Catalytic Activity and Selectivity. J. Mol. Catal. 1984, 26, 375-384.

(24) Lindlar, H.; Dubuis, R. Palladium Catalyst for Partial Reduction of Acetylenes. Org. Synth. 1966, 46, 89-92.

(25) Li, J. F.; Tian, X. D.; Li, S. B.; Anema, J. R.; Yang, Z. L.; Ding, Y.; Wu, Y. F.; Zeng, Y. M.; Chen, Q. Z.; Ren, B.; Wang, Z. L.; Tian, Z. Q. Surface Analysis Using Shell-Isolated Nanoparticle-Enhanced Raman Spectroscopy. Nat. Protoc. 2013, 8, 52-65.

(26) Turkevich, J.; Stevenson, P. C.; Hillier, J. A Study of the Nucleation and Growth Processes in the Synthesis of Colloidal Gold. Discuss. Faraday Soc. 1951, 11, 55-75.

(27) Cao, L.; Zhu, T.; Liu, Z. Formation Mechanism of Nonspherical Gold Nanoparticles during Seeding Growth: Roles of Anion Adsorption and Reduction Rate. J. Colloid Interface Sci. 2006, 293, 69-76.

(28) Kobayashi, Y.; Correa-Duarte, M. A.; Liz-Marzán, L. M. Sol-Gel Processing of Silica-Coated Gold Nanoparticles. Langmuir 2001, 17, 6375-6379.

(29) Ren, B.; Yao, J. L.; Li, X. Q.; Cai, W. B.; Mao, B. W.; Tian, Z. Q. A New Progress in Surface Raman Spectroscopy of Platinum Electrode Surfaces. Int. J. Vib. Spectrosc. 1996, 1, 7.

(30) Graham, G. W.; Weber, W. H.; McBride, J. R.; Peters, C. R. Raman Investigation of Simple and Complex Oxides of Platinum. J. Raman Spectrosc. 1991, 22, 1-9.

(31) Mrozek, M. F.; Weaver, M. J. Periodic Trends in ElectrodeChemisorbate Bonding: Ethylene on Platinum-Group and Gold Electrodes as Probed by Surface-Enhanced Raman Spectroscopy. J. Phys. Chem. B 2001, 105, 8931-8937.

(32) Huang, Y. F.; Kooyman, P. J.; Koper, M. T. M. Intermediate Stages of Electrochemical Oxidation of Single-Crystalline Platinum Revealed by in Situ Raman Spectroscopy. Nat. Commun. 2016, 7, 17.

(33) Lin, W.; Herzing, A. A.; Kiely, C. J.; Wachs, I. E. Probing MetalSupport Interactions under Oxidizing and Reducing Conditions: In Situ Raman and Infrared Spectroscopic and Scanning Transmission Electron Microscopic-X-Ray Energy-Dispersive Spectroscopic Investigation of Supported Platinum Catalysts. J. Phys. Chem. C 2008, 112, 5942-5951. 
(34) Williams, C. T.; Tolia, A. A.; Weaver, M. J.; Takoudis, C. G. Surface-Enhanced Raman Spectroscopy as an In Situ Real-Time Probe of No Reduction over Rhodium at High Gas Pressures. Chem. Eng. Sci. 1996, 51, 1673-1682.

(35) Li, J. F.; Anema, J. R.; Wandlowski, T.; Tian, Z. Q. Dielectric Shell Isolated and Graphene Shell Isolated Nanoparticle Enhanced Raman Spectroscopies and Their Applications. Chem. Soc. Rev. 2015, 44, 8399-8409.

(36) Socrates, G. Infrared and Raman Characteristic Group Frequencies, 3rd ed.; John Wiley \& Sons Ltd: Chichester, England, 2001.

(37) Shen, W.; Lin, X.; Jiang, C.; Li, C.; Lin, H.; Huang, J.; Wang, S.; Liu, G.; Yan, X.; Zhong, Q; Ren, B. Reliable Quantitative SERS Analysis Facilitated by Core-Shell Nanoparticles with Embedded Internal Standards. Angew. Chem., Int. Ed. 2015, 54, 7308-7312.

(38) Ando, J.; Asanuma, M.; Dodo, K.; Yamakoshi, H.; Kawata, S.; Fujita, K.; Sodeoka, M. Alkyne-Tag SERS Screening and Identification of Small-Molecule-Binding Sites in Protein. J. Am. Chem. Soc. 2016, 138, 13901-13910.

(39) Weckhuysen, B. M. Catalysts Live and up Close. Nature 2006, 439, 548.

(40) Jang, Y. H.; Hwang, S.; Oh, J. J.; Joo, S. W. Adsorption Change of Cyclohexyl Acetylene on Gold Nanoparticle Surfaces. Vib. Spectrosc. 2009, 51, 193-198.

(41) Joo, S. W.; Kim, K. Adsorption of Phenylacetylene on Gold Nanoparticle Surfaces Investigated by Surface-Enhanced Raman Scattering. J. Raman Spectrosc. 2004, 35, 549-554.

(42) Kennedy, D. C.; McKay, C. S.; Tay, L.; Rouleau, Y.; Pezacki, J. P. Carbon-Bonded Silver Nanoparticles: Alkyne-Functionalized Ligands for SERS Imaging of Mammalian Cells. Chem. Commun. 2011, 47, 3156-3158.

(43) Sohn, Y.; Wei, W.; White, J. M. Phenylacetylene on $\mathrm{Cu}(111)$ : Adsorption Geometry, Interfacial Electronic Structures and Thermal Chemistry. J. Phys. Chem. C 2007, 111, 5101-5110.

(44) Parker, W. L.; Siedle, A. R.; Hexter, R. M. Raman Spectroscopic Study of Acetylene on Supported Rhodium Catalysts. J. Am. Chem. Soc. 1985, 107, 264-266.

(45) Feilchenfeld, H.; Weaver, M. J. Adsorption of Acetylene on Rhodium- or Platinum-Modified Silver and Gold Electrodes: A Surface-Enhanced Raman Study. J. Phys. Chem. 1991, 95, 7771-7777.

(46) Polzonetti, G.; Carravetta, V.; Russo, M. V.; Contini, G.; Parent, P.; Laffon, C. Phenylacetylene Chemisorbed on Pt (111), Reactivity and Molecular Orientation as Probed by NEXAFS Comparison with Condensed Multilayer and Polyphenylacetylene. J. Electron Spectrosc. Relat. Phenom. 1999, 98-99, 175-187.

(47) Wojdyr, M. Fityk: A General-Purpose Peak Fitting Program. J. Appl. Crystallogr. 2010, 43, 1126-1128.

(48) Gómez, R.; Solla-Gullón, J.; Pérez, J. M.; Aldaz, A. SurfaceEnhanced Raman Spectroscopy Study of Ethylene Adsorbed on a $\mathrm{Pt}$ Electrode Decorated with Pt Nanoparticles. ChemPhysChem 2005, 6, 2017-2021.

(49) Heaviside, J.; Hendra, P. J.; Tsai, P.; Cooney, R. P. Adsorption and Polymerization of Acetylene on Oxide Surfaces. A Raman Study. J. Chem. Soc., Faraday Trans. 1 1978, 74, 2542-2549. 